\title{
Culture of Brand Origin (COBO): The Impacts of Language and Linguistics on Purchase Intention of a Brand
}

Amran Harun

\author{
Associate Professor, Faculty of Business, Economics and Accountancy, Universiti Malaysia Sabah \\ Kota Kinabalu, Sabah, Malaysia; Email: aharun@ums.edu.my
}

\begin{abstract}
Nabsiah Abdul Wahid
Associate Professor, Graduate School of Business, Universiti Sains Malaysia, Penang, Malaysia Email: nabsiah@usm.my

Osman Mohamad

Professor, Graduate School of Management, Multimedia University, Selangor, Malaysia Email: osman.mohamad@mmu.edu.my

\section{Jaratin Lily (Corresponding Author)}

Faculty of Business, Economics and Accountancy, Universiti Malaysia Sabah Kota Kinabalu, Sabah, Malaysia; Email: jaratin@ums.edu.my

\section{Charlie Albert Lasuin}

Faculty of Business, Economics and Accountancy, Universiti Malaysia Sabah Kota Kinabalu, Sabah, Malaysia; Email: calsbert@ums.edu.my
\end{abstract}

Doi:10.5901/mjss.2016.v7n1p32

\section{Abstract}

This paper provides new insights into origin effect by focusing on new significant parameters pertaining to culture namely language and linguistics factors. It is postulated that the identification of culture of brand origin (COBO) on the basis of its language, and evaluation on linguistics components in a brand name can influence consumers to purchase a brand. The study is quantitative in nature using a survey method on consumer samples on which they were asked to evaluate food products sold under four different Malaysian brand names whereby each brand name is representing four different languages (i.e. Bahasa Malaysia, Mandarin, Tamil and English) that are used for communication within the major ethnic groups in the country. Results from a survey of 504 working adults comprised of Malay, Chinese and Indian respondents indicated that the elements in COBO have an influence on consumers' purchase intention. The study findings imply the importance of COBO as a tool to predict consumer's intention to purchase by using linguistic components found in product's brand name. Managers can appreciate the usefulness of language as a strategy in brand positioning and determining the most effective linguistic pattern to be applied in a brand name.

Keywords: Culture of Brand Origin (COBO), Language, Brand Name Linguistics, Malaysian Brands, Purchase Intention

\section{Introduction}

Brand name is a tool already acknowledged in the creation of social interaction between marketers and targeted consumers (Li and Shoostari, 2003). Thus, firm's ability to create a strong product brand is one of the key factors for the firm's competitive advantages as well as their survival (Zablah, Brown and Donthu, 2010). The success for achieving strong brand creation has been associated with many factors; and country of origin (COO) is one of them. Although COO has been popularly used to predict consumer's behavior in particular purchase intention; over the years, the literature also note some methodological issues linked to its usage. Examples include issues on its accuracy (Peterson and Jolibert, 1995) and complicated evaluation process (Lim and O'Cass, 2001). The quest to solve these issues however 
resulted in various attempts made by researchers to refine the flaws by focusing on the 'origin-effect' evaluation, or, by investigating other tools or mechanisms that can predict consumer behavior. Suggestion to focus on the role of culture in COO was one of the outcomes from attempts to correct COO's so called defect. Lim and O'Cass (2001) suggested the inclusion of cultural element in $\mathrm{COO}$, arguing on the importance of culture influences on consumer's behavior, and thus introducing the birth of Culture of Brand Origin (COBO).

The importance of culture is highlighted mostly due to the belief that consumers with different culture background will display a distinct set of views and attitudes, different tastes and inclinations as well as distinctive values amongst them (Suh and Kwon, 2002). Today, the use of culture elements by marketers has been vast in particular advertisers. One of the culture elements that are popular is the use of local language within an advertised brand name. Brands with names that are sounded like they are locally produced are believed to attract locals more, which will help boost the brand name further. An established Malaysian company, UNZA for instance, has proven the successfulness of this strategy in marketing its product locally and overseas. Maxcleen 9, the brand name of UNZA's washing detergent in Malaysia, is marketed in foreign countries under different brand names that make use of the target country's local language. For example, the brand name for the product varies, for example it is called Way Way in Singapore whilst Vigor 33 in Hong Kong (Amran, Nabsiah, Osman and Jenny, 2011). Maxcleen's success indicates the importance for marketer to build country's culture understanding which is translated via the choice of changing a product's brand name to suit local taste. Language is after all considered as the most crucial element of culture (Terpstra and Sarathy (1997), or the 'mirror of culture' (Czinkota and Ronkainen, 1995).

In the Malaysian context, it is observed that local brand names are always important in giving indication of the ethnic origin only for those products that are culture sensitive, food products for instance. To name a few, the brand names such as Adabi, Alagapas and Lee Kum Kee represent the Malay, Indian and Chinese communities respectively. These ethnic groups form the three major races in the country. Thus, the use of the Malay language, also known as Bahasa Malaysia, or the use of languages of the other ethnic groups in a brand name, may indirectly indicate the origin of the brands. Boddewyn, Soehl and Picard (1986) have a positive view on this branding strategy when they insisted that nondurable consumer products; for example, must always be associated with a local culture. De Mooij (1995) also addressed a similar concern by highlighting that for the nondurable products, food products for instance, these products normally reflect and are tied to a specific culture. The main reason for the branding strategy in Malaysia to use various languages, which reflect different ethnic origins, is due to the diversity of the Malaysian culture, with its multi-ethnic subcultures. According to Yacob (2005), Malaysia is formed by a multi-racial, multi-lingual, multi-cultural, as well as multireligious society. Malaysia apparently is recognized as one of the linguistically heterogeneous nations (Banks and Textor, 1963).

A study investigating the effects of language (i.e. Chinese and English) on consumer's memory managed to identify and link the importance of linguistic characteristics on consumer's memory of brand names (Schmitt, Pan and Tavassoli, 1994). The researchers found that consumer's learning of brand names via audio or visual have different effect on their memory. The findings also indicate the need to investigate further on the culture's role played by language and the linguistic properties in a brand name (as indicator of origin) on how consumers react towards the product. The linguistic nature of a brand name has been an area that is still lacking research attention today and therefore this present study will investigate the impacts of four languages and linguistics properties namely Bahasa Malaysia, Mandarin, Tamil and English on consumer intention to purchase of a brand name.

\section{New Conceptual Definition of COBO}

Lim and O'Cass's (2001) work on identifying culture that is associated with a brand origin made them the first researchers to acknowledge the importance of culture as an origin indicator for a brand. Much of Lim and O'Cass's (2001) researches address the declining relevancy of $\mathrm{COO}$, providing legitimate reasons for the introduction of $\mathrm{COBO}$. More importantly, the study highlights the significance of $\mathrm{COBO}$ as a proper means of product origin evaluation when consumers are not able to understand the various and complicated concepts of COO information. Indeed, Lim and O'Cass's study (2001) was in line with Takor and Kohli's (1996) proposition of examining brand origin rather than evaluating the COO information. The basis for this notion, according to Lim and O'Cass (2001), is due to the fact that the traditional concept of COO is found to be no longer relevant in today's marketing environment. Brand origin, as described earlier, is the way a brand is perceived by consumers in relation to the origin of a brand, either from a place, a region or a country (Thakor and Kohli 1996). Even though COO and Brand Origin concepts may look identical, there are perceptible distinctions between the two aforementioned concepts. COO studies normally investigate the effect of 'made-in country', requiring immense effort to understand perception of consumers; where the product is manufactured, where the parts or the product materials 
come from, and where the product is designed. In contrast, Brand Origin heightens the value of a brand regardless of manufacturing location. For instance Nike, a brand that is originating from the United States of America, which is manufactured in China, yet most people around the world still recognize Nike as an American brand regardless of where the brand was produced (Amran, Nabsiah, Osman and Jenny, 2011)

In concurrence with the concept proposed by Thakor and Kohli (1996), Lim and O'Cass (2001) investigate brand origin by focusing on the cultural aspects of a brand and produced the term 'Culture of Brand Origin' (COBO). Several researchers have also highlighted that linguistic properties of a brand name may indicate product's origin (Li and Shoostari, 2003; Lerclerc, Shmitt and Dube, 1994). Importantly, Li and Shoostari (2003) support the above assumption when they explain that a brand name plays a role in a society as it serves as a social interaction tool between marketers and consumers. Brand name's intrinsic quality as an information cue for cultural origin is analogous to the notion of Lim and O'Cass (2001) that COBO is more significant. It is therefore assumed that the linguistic properties of a brand name can be a source of information for brand origin. Firstly, it is proclaimed that a language is in fact of a cultural origin construct, an important role in addressing the issue in international branding (Warden et al, 2002). Secondly, as identified by Usunier and Shamer (2002), consumers usually employ local language and culture as basis to create brand identity. Finally, consumer perceptions are different across cultures, said to be caused by cultural factors rather than the 'made in country' effect (Herche, 1990, 1994). Hence, it is reasonable to highlight here that COBO concept should be examined through the brand name, and the evaluation should be made on the language and its linguistic properties. To conclude, the present study re-conceptualizes the definition of СОВO, which the term was first defined by Lim and O'Cass (2001). This research will bring to light that language and linguistic properties of a brand name are the cultural characteristics that provide origin information to consumers. Therefore, it is conceptualized that a brand name linguistics, which consists of a language, word, sound and literal meaning, can provide a distinctive identity to a brand especially pertaining to brand origin information.

\section{The Influence of $\mathrm{COBO}$ on Purchase Intention}

This study will observe the two proposed important variables in COBO; the language which can be used to identify the culture of brand origin and evaluation of brand name linguistics. In other words, identification of culture of brand origin will be made upon understanding how consumers identify brand origin from language perspective. The second variable, perception of brand name linguistics, focuses on how consumers perceive the linguistic properties of a brand name in relation to their purchase intentions. Speech Accommodation Theory (SAT) will be useful in gaining an understanding of the underlying reasons of why one ethnic group in Malaysia has a preference and purchases a brand name that uses their ethnic language over other brand names written in different languages. Overall, this theory suggests that a favorable reaction among the target audience is expected when speakers of a different language are able to adjust or accommodate their language to the audience's language style. In addition, Giles and Powesland (1975: p. 167) contend that the effort of changing the communication style to accommodate to the language of the listeners is primarily to obtain approval from the listeners. The reverse reaction is assumed when the speakers could not adjust their language to the target audience's linguistic style. This theory is generally applied to understand the linguistic variations in the social interactions and more importantly to understand the consequences arising from this interaction, such as the feelings, values, attitudes and perceptions that evolved between the speakers and the recipients (Beebe and Giles, 1984). Many past studies have applied the theory in the context of advertising (eg. Karande, 2004; Koslow et.al, 1994; Deshpande and Stayman, 1994), in mass communication (Montgomery, 1988) and also in the evaluation of languages used in packaging (De Run and Fah, 2005). An application of the Speech Accommodation theory is important for this present study which can provide useful insights into how Malaysian consumers comprised of various linguistic groups react to the many languages of brand names available in the local market. This theory will justify the existence of a different pattern of Malaysian consumer behavior, considering their reactions towards brand name of different languages. In addition, the SAT theory will provide a clear picture that one ethnicity is inclined to react positively to a brand name in which the language is similar to their own language, and vice versa.

Lim and O'Cass' (2001) study adopts the identification of brand's cultural origin (based on eastern and western cultures) to comprehend COBO's effect particularly among young Singaporean consumers on attitude and intention to purchase brands of fashion apparel. It was revealed that young consumers in Singapore are able to trace the cultural origin (eastern or western) of the apparel's brands via the names of brand. In contrast, majority of the respondents in Lim and O'Cass' (2001) study failed to indicate the country of origin of the brands. Lim and O'Cass' (2001) conclude that perception of culture of brand origin significantly affects consumer attitude and purchase intention of the brand. Prior to Lim's and O'Cass' (2001) study, another research undertaken by Batra, R., Ramaswamy, V., L. Alden, D., M. Steenkamp, 
J.B.E and Ramachander, S. (2000) investigate the way urban consumers in India react towards brands which are perceived to be both local and non-local brands. The results of their study indicated that the perception of local/non-local brand origin among Indian urban consumers has a great influence on their attitudes towards the brand. In a similar vein, a recent study by Schuiling and Kapferer (2004) adopted the perception of local and global brands to identify the origin of a brand. Their study found that consumers in the United Kingdom, Germany, France and Italy highly favor their local brands over global brands. Local brands are largely preferred by the respondents when the local brands receive a high level of awareness and brand trust.

In the context of COBO however, assessment of brand origin identification is subject to cultural effects influence. The use of linguistics to evaluate $\mathrm{COBO}$ is vital considering the importance of language in a brand name to the consumers of different linguistic backgrounds. For example, Japanese multinational companies acknowledge the significant effect of language when marketing products to Middle Eastern countries by altering their brand names to increase product acceptance by the host culture (Leonideu, 1996). Thus, this study will focus on understanding the effect of language and linguistics components of a brand name, particularly as information source about cultural origin of a brand. The hypotheses are formulated as follows:

H1: A language (Bahasa, Chinese, Tamil and English) which is identified as relevant to local culture is positively related with purchase intention of a brand.

$\mathrm{H}$ 2: A language (Bahasa, Chinese, Tamil and English) which is identified as relevant to foreign culture of a brand is negatively related with purchase intention of a brand.

Understanding that purchase intention is the ultimate goal for marketers in order to ensure brand names acceptance is concurred by Chan and Huang (1997) when they stress that the main objective of having a good name linguistically is to capture the interest of consumers. Due to the proper use of linguistic rules to form a good brand name, the right choice of a name can be expected to encourage consumers to purchase the brand. Continuing the effort to identify reasons behind specific brands choice, Lerman (2000) examines the effect of familiar and unfamiliar morphemes on intention to purchase a brand and found that this relationship is significant. His study discovers that familiar morphemes used in a brand can lead to high purchase intention among native speakers, whilst the use of unfamiliar morpheme will result in a high purchase intention among the non-native speakers. Pan and Schmitt (1996) examine the link between the script and sound of a brand name and found that these linguistic elements (script and sound) can determine purchase intention. Purchase intention is higher for Americans when the sound is matching, whilst Chinese intend to buy a brand when the script of a brand name is matched (Pan and Schmitt 1996). In addition, Schmitt and Zhang (1998) also support the notion that brand name linguistics can influence purchase intention of a brand. They specifically examine the influence of classifiers on consumer behavior (purchase intention) among individuals from China, Hong Kong, Japan, and America. The study provides evidence that perception of the use of a classifier in a brand name can affect consumer purchase intention of that brand name. Therefore, this study will extend these knowledge by understanding the three components of brand name linguistics and their functions in affecting consumer behavior of the main ethnicities in Malaysia namely Malay, Chinese and Indian. These groups will evaluate four languages of brand names, which are Bahasa Malaysia, Chinese, Tamil and English. The Sapir-Whorf hypothesis theory (Whorf, 1941) has unearthed the verity of the differences in the perception, attitude and behavior amongst the cultural groups that come from a different linguistic background. One reason for such differences is that the groups speak different languages.

The proposed hypotheses are generated as follows:

H3: The perception of morphology of a brand (Bahasa, Chinese, Tamil and English) is positively related with purchase intention

H4: The perception of phonetics of a brand (Bahasa, Chinese, Tamil and English) is positively related with purchase intention

H5: The perception of semantics of a brand (Bahasa, Chinese, Tamil and English) is positively related with purchase intention

Derived from the literature discussion, the study proposes a research model as shown in Figure 3.1. 


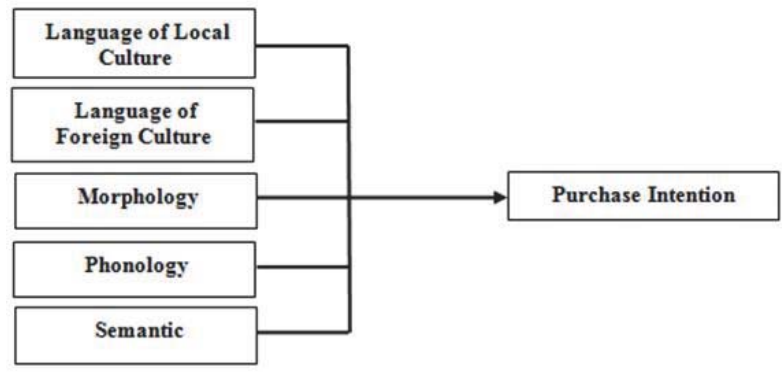

Figure 3.1: The Conceptual Framework

\section{Research Methodology}

This study required the inclusion of working individuals who were at least 18 years of age, and the sampling frame consisted of 504 individuals. Out of 504 respondents, 300 were selected from among Malay respondents, 130 were Chinese respondents, and a total of 74 respondents were chosen from the Indian population. The size of each of these ethnic groups corresponds approximately to the composition ratio of the major ethnic groups in Malaysia (60\% Malay, $26 \%$ Chinese and 8\% Indian: National Census, 2002). Mall intercept procedure was adopted whereby the samples were drawn from the shopping malls in four states, namely Penang, Johor, Selangor and Pahang. These states were chosen principally due to the fact that the states have a fair distribution of Indian population, as well as the other two races, namely the Malay and Chinese.

The brands in this study were selected from among the local food brands familiar to Malaysian consumers. This approach was undertaken for two important reasons. First, a majority of local food producers were found to use their own native language for the name of their brands. Second, some researchers have stressed the importance of associating food products with a local culture (eg. Boddewyn, Spehl and Picard, 1986). Therefore, this study was confined to local food brand names and specifically names representing Bahasa Malaysia, Chinese, Tamil and English. The Bahasa Malaysia brand name was chosen mainly for its role as the national language. Therefore, Malaysians are assumed to have the perception that the use of Bahasa Malaysia in a brand name will reflect the local culture as the brand has a strong image amongst users of the local language. In contrast, the English brand name was chosen primarily due to its projection of a foreign image (Chen, Warden and Chang 2006), even though the language is the second Malaysian official language. A preliminary study was conducted among 51 school teachers of different cultural background and ages to obtain the four familiar food brand names. Results from this preliminary study produced two particularly familiar brand names, specifically Jati (Bahasa), Life (English), Alagappas (Tamil) and Singlong (Chinese). Therefore these brand names were used in the study.

A survey approach was employed whereby all the respondents' evaluations of the COBO and purchase intention were elicited from a questionnaire. The questionnaire consisted of three parts. The first part of the questionnaire comprised questions pertaining to the evaluation of $\mathrm{COBO}$. The questions for identification of $\mathrm{COBO}$ were adopted and adapted from Lim and O'Cass (2001), Batra et al. (2003) and Steenkamp et al. (2003). These questions were evaluated with a five-point Likert scale, ranging from (1) strongly disagree to (5) strongly agree. The second part of the questionnaire was the evaluation of the brand name linguistics which the scales were adopted and adapted from the past prescriptive studies pertaining to the characteristics of a brand name. The scale is a three dimension variable namely (1) perception of the morphology (2) perception of the phonetics (3) perception of the semantics. All of these questions were designed to assess the two brand names with a five-point Likert scale in which the end points were labeled "strongly disagree" and "strongly agree". In the third part of the questionnaire, respondents were asked to evaluate their interest in purchasing the brand names which is the dependent variable in this study. These questions were mainly adopted from the scales used in the study by Grace and O'Cass (2005). All items in this part were measured on a five-point Likert scale which (1) denotes strongly disagree to (5) which denotes strongly agree. The last section of the questionnaire included questions to review the demographic characteristics of respondents such as age, gender, race, educational level, monthly income and respondents' native language.

The analysis utilized the SPSS statistical program and specifically utilized multiple regression analysis which was employed to analyze the relationship of all variables in the study. Since this study focuses on the purchase intention of a 
brand name in four languages, namely Bahasa Malaysia, Chinese, Indian and English the multiple regressions were performed separately for each of the languages.

\section{Results}

\subsection{Descriptive Analysis}

Referring to results in Table 1, it was found that a high percentage of the respondents (90.3\%) perceived the Bahasa Malaysia brand name, the 'Jati' brand, to be significant to the local culture. For the Alagappas brand which represents the Tamil language, more than half of the respondents (57.9\%) 'agree' that the brand name suits the local culture. For Singlong, it is interesting to observe the split in results: for example 35.3 percent of the respondents are not sure about the Culture of Brand Origin, whilst 34.1 percent of the respondents consider the brand as representing a foreign culture, and the rest (30.6\%) 'agree' that the brand name suits the local culture. However, for the English brand name (Life) 32 percent of the respondents could not identify the cultural origin of the brand, whilst almost half of the respondents (49\%) said that this brand is of a foreign culture. Only a small number of respondents (19\%) agreed that this brand represents the local culture. It is not surprising to have respondents agreeing to the perception that the use of English in a brand name suits the local culture since English brand names are common in the local market. It would seem that the Bahasa Malaysia brand name is perceived by the majority of respondents as representing the local culture, in contrast to the remaining brand names.

Table 1: Results of Culture of Brand Origin Identification

\begin{tabular}{lcc}
\hline Brand Names & Frequency & Percentage \\
\hline Jati & 455 & \\
Local Culture & 17 & 90.3 \\
Foreign Culture & 32 & 3.4 \\
Unsure & 292 & 6.3 \\
\hline Alagappas & 160 & 57.9 \\
Local Culture & 52 & 31.8 \\
Foreign Culture & & 10.3 \\
Unsure & 154 & \\
Singlong & 172 & 30.6 \\
Local Culture & 178 & 34.1 \\
Foreign Culture & & 35.3 \\
Unsure & 96 & \\
Life & 247 & 19.0 \\
Local Culture & 161 & 49.0 \\
Foreign Culture & 32.0 \\
Unsure &
\end{tabular}

Note: $\mathrm{N}=504$

A summary of assumed origin of the products is presented in Table 2. The results indicate that more than 40 percent of the respondents perceived the English brand name (Life) to be a foreign-made food product. Only a small percentage of respondents (17.9\%) said that this brand is locally produced. However, for the Bahasa Malaysia brand name (Jati), 92.3 percent of respondents in general identified the brand as a local product. The English brand name, however, is perceived to be foreign made. It can be seen that for both the Bahasa Malaysia and the Tamil language brand names (Jati and Alagappas), respondents in general identified these brands as local products with a percentage of 92.2 and 63.1 percent respectively. As for the Chinese brand name (Singlong), almost half of the respondents (48\%) were not able to identify the origin of the brand and most of the respondents (33.7\%) assumed the brand to be a foreign product. Therefore, it is worth highlighting here that the Bahasa Malaysia brand name is relevant in the Malaysian branding context as this language can signify the local culture and to the consumers the language is well suited for use by local products. 
Table 2: Results on Origin of the Product

\begin{tabular}{lcc}
\hline Brand Names & Frequency & Percentage \\
\cline { 1 - 2 } & & \\
Local product & 465 & 92.2 \\
Imported product & 18 & 3.6 \\
Unsure & 21 & 4.2 \\
\hline Alagappas & & \\
Local product & 318 & 63.1 \\
Foreign product & 130 & 25.8 \\
Unsure & 56 & 11.1 \\
\hline Singlong & & \\
Local product & 92 & 18.3 \\
Foreign product & 170 & 33.7 \\
Unsure & 242 & 48.0 \\
\hline Life & & \\
Local product & 90 & 17.9 \\
Foreign product & 210 & 41.6 \\
Unsure & 204 & 40.5 \\
\hline
\end{tabular}

Note: $\mathrm{N}=504$

\subsection{Factor Analysis}

Table 3: Results of the Factor Analysis for Independent Variables

\begin{tabular}{|c|c|c|c|c|c|}
\hline & F1 & F2 & F3 & F4 & F5 \\
\hline \multicolumn{6}{|l|}{ Phonetic } \\
\hline The name is pleasant to read & .836 & & & & \\
\hline The name is pleasant to hear & .820 & & & & \\
\hline The sound of brand name is unique & .712 & & & & \\
\hline The name is simple to pronounce & .643 & & & & \\
\hline $\begin{array}{l}\text { The name is easily pronounced in } \\
\text { other languages }\end{array}$ & .552 & & & & \\
\hline Semantics & & & & & \\
\hline The meaning is appealing & & .799 & & & \\
\hline The meaning indicates product attributes & & .792 & & & \\
\hline The name has a positive meaning & & .711 & & & \\
\hline The name has a unique meaning & & .650 & & & \\
\hline \multicolumn{6}{|l|}{ Local culture } \\
\hline The language is suitable for a local product & & & .839 & & \\
\hline The language reflects Malaysian culture & & & .745 & & \\
\hline I think local consumers buy the brand names because & & & & & \\
\hline $\begin{array}{l}\text { of the language } \\
\text { Morphology }\end{array}$ & & & .694 & & \\
\hline The word is easy to recognize & & & & .839 & \\
\hline The word is easy to remember & & & & .819 & \\
\hline \multicolumn{6}{|l|}{ Foreign culture } \\
\hline \multirow{2}{*}{\multicolumn{5}{|c|}{$\begin{array}{l}\text { The language used in this brand name is suitable for foreign products } \\
\text { The language used in this brand name reflects foreign culture }\end{array}$}} & .792 \\
\hline & & & & & .775 \\
\hline $\begin{array}{l}\text { Eigenvalue } \\
\% \text { of Variance explained } \\
\text { Kaiser-Meyer-Olkin (KMO) } \\
\text { Bartlett's test of Sphericity }\end{array}$ & 4.15 & 1.89 & 1.78 & 1.45 & $\begin{array}{l}1.16 \\
61.519 \\
0.766 \\
2398.635\end{array}$ \\
\hline
\end{tabular}

Note: Extraction Method: Principle Component Analysis

Rotation method: Varimax with Kaiser Normalization

Table 3 shows the result of factor analysis in the eighth iteration. These five factors accounted for $61.52 \%$ of the total variance, with the Kaiser-Meyer Olkin (KMO) measure of sampling adequacy results reported at 0.766 . This KMO value indicates that the sampling adequacy for this study is within the acceptable range and the distribution of values is satisfactory for conducting this analysis. The Bartlett's test of sphericity is significant at $0.0 \mathrm{p}$-value and this value confirms the multivariate normality of the data.

All anti-image correlation items yield values greater than 0.50 and the values are from 0.594 to 0.893 . The eigenvalues are 4.148, 1.892, 1.778, 1.454, and 1.162 for Factor 1, Factor 2, Factor 3, Factor 4, and Factor 5 respectively and these values met the eigenvalues requirement of a minimum of 1 , which concurs with Hair, Black, Babin, Anderson and Tatham (1998). In addition, all the items for each factor had factor loadings of 0.50 and above. In factor 1 , 
the factor loading values are between 0.552 and 0.836 . Factor 2 yields factor loading values from 0.650 to 0.799 ; factor 3 has factor loadings in the range of 0.694 to 0.839 ; factor 4 shows factor loadings in the range of 0.647 to 0.831 ; and finally in factor 5 , the factor loading values are from 0.775 to 0.792 . The three conceptual dimensions for brand name linguistics are retained as the result from this analysis. These are: the perception of the phonology of brand names (Factor 1); perception of the semantics of brand names (Factor 2); and the perception of the morphology of brand names (Factor 5).

The factor analysis is also performed on the dependent variable (purchase intention of brand name) and the result is shown in Table 4. The result shows that this variable is also a uni-factorial when all items are loaded into one factor. Hence, it can be concluded that the convergent validity has been established when all items in the dependent variable fall into 1 factor as theorized (Campbell and Fiske, 1959). In addition, the result shows a significant Bartlett's test of sphericity with a p-value of 0.00 and Kaiser Meyer Olkin is at 0.635 . The item loadings for this factor are rather high with a minimum loading of 0.766 . It is also noted that all of the anti-image correlation items have values above 0.50 . The eigenvalue for this factor is greater than 1 in which the value is at 2.131. No item is found to violate the assumptions for factor analysis suggested by Hair et. al. (1998), thus no item in this factor was dropped.

Table 4: Factor Analysis for Purchase Intention of Brand Name-The First Iteration

\begin{tabular}{ll}
\hline Items & $\begin{array}{c}\text { Factor Loading } \\
\text { F1 }\end{array}$ \\
\hline I will probably use this brand in the future & .909 \\
I am likely to use this brand in the future & .848 \\
I have every intention of using this brand in the future & .766 \\
\hline Eigenvalue & 2.131 \\
\% of Variance explained & 71.036 \\
Kaiser-Meyer-Olkin (KMO) & 0.635 \\
Bartlett's test of Sphericity & $\mathbf{5 3 4 . 7 3 5}$ \\
\hline
\end{tabular}

Note: Extraction Method: Principle Component Analysis

a. 1 component extracted

\subsection{Results of Multiple Regression Analysis}

Results in Table 6 explain that for the Bahasa brand name (Jati), the regression analysis produces a variance of 32.1 percent for the dependent variable (purchase intention of the Jati brand name) with the inclusion of independent variables, i.e. the identification of СОВO and perception of brand name linguistics. For the identification of COBO, identification of foreign culture $(\beta=.074, p>.0 .80)$ is found to have no significant relationship with purchase intention for the Jati brand name. Nevertheless, identification of local culture for the Jati brand name $(\beta=0.140, p<0.005)$ is found to be significant in explaining its positive relationship with purchase intention for the Bahasa Malaysia brand name. This is also true for the perception of the semantics of Jati $(\beta=0.174, p<0.000)$ which produces a significant and positive relationship with purchase intention of the Jati brand name. Upon closer examination, two out of three dimensions of the perception of brand name linguistics are found to be insignificant predictors for purchase intention of the Jati brand name, namely perception of morphology ( $\beta=.049, p>0.293)$ and perception of phonetics $(\beta=.053, p>.275)$.

Table 6: Summary Results for the Influence of Major Variables on Purchase Intention (Standardized Beta)

\begin{tabular}{lllll}
\hline Purchase Intention of the Brands & & & \\
& Bahasa Malaysia & Tamil & Chinese & English \\
Local culture & $0.140^{* *}$ & $0.176^{* *}$ & $0.246^{* * *}$ & 0.005 \\
Foreign culture & 0.074 & -0.044 & -0.006 & $0.079^{*}$ \\
Morphology & 0.049 & $0.105^{* *}$ & $0.168^{* * *}$ & $0.274^{* *}$ \\
Phonology & 0.053 & $0.217^{* *}$ & 0.077 & 0.080 \\
Semantic & $0.174^{* *}$ & $0.096^{* *}$ & 0.043 & $0.219^{* * *}$ \\
\hline
\end{tabular}

Note: ${ }^{*} p<0.05,{ }^{*} p<0.01, p<0.001$ 
Only two dimensions of independent variables have a positive significant relationship with purchase intention of the Singlong (Chinese) brand. These dimensions are: (1) the identification of local culture $(\beta=.246, p<.000)$; and (2) the perception of the morphology $(\beta=.168, p<.000)$. The rest of the three dimensions (identification of foreign culture, perception of the semantics and perception of the phonetics of Singlong) are not significant predictors for purchase intention of the Singlong brand when all the $p$ values are found to be greater than 0.00 at 5 significant levels.

For the Tamil brand name; Alagappas, the inclusion of these independent variables has produced 24.7 percent variance in the dependent variable. It is found that identification of local culture $(\beta=0.176, p<.000)$ is found to be a significant predictor for intention to purchase of the Alagappas brand with a positive relationship. The identification of foreign culture $(\beta=-0.044, p>$.294) is not significant in its relationship with purchase intention of the Alagappas brand. In terms of the perception of brand name linguistics, all the three dimensions are found to have a positive and significant relationship with intention to purchase the Alagappas brand. They are: (1) the perception of the morphology ( $\beta=0.105$, $p<.023)$; (2) the perception of the phonetics $(\beta=0.217, p<.000)$; and (3) the perception of the semantics $(\beta=0.096$, $p<.030)$.

As for the English brand name, the regression results in Table 3 show that 30.2 percent of variations in intention to purchase the Life brand name are explained by independent variables. Only three dimensions are found to be significant. The dimensions are: (1) the identification of foreign culture $(\beta=0.079, p<.049) ;(2)$ the perception of the semantics $(\beta=0.219, p<.000)$; and (3) the perception of the morphology $(\beta=0.274, p<.000)$. The rest of the dimensions are found not to have a correlation with purchase intention of the Life brand name when all the $p$ values are greater than 0.00 at 5 percent significance level.

\section{Discussions}

It has been demonstrated from the findings that the identification of local culture has a positive influence on purchase intention of the Bahasa Malaysia, Tamil and Chinese brand names. With this finding, it can be pointed out that this dimension is the most influential factor that leads consumers to purchase the local food brands. One possible reason that may explain the importance of this dimension is that these languages (Bahasa Malaysia, Tamil and Chinese) are the languages spoken by the three major ethnic groups in Malaysia, namely the Malay, Indian and Chinese groups. Thus, respondents in this current study perceive and agree that these languages are a significant part of Malaysian culture. In addition, they perceive the languages of the brand names as reflecting the cultural origin of the brands and consequently, this factor influences their purchase intention of the brands. This interesting finding, that the Bahasa Malaysia, Chinese and Tamil languages are perceived to signify the local culture, is in harmony with the fact that Malaysia is a nation with a multilingual, multicultural and multiracial society (Omar, 1992). Indeed, it is to be expected that respondents will relate to the Chinese and Tamil brand names as brands imported from China or India as evidenced by the languages. However, due to the fact that Malaysians are in fact a pluralistic and multicultural society the blend of these different races produce an acceptance of the fact that the Bahasa Malaysia, Tamil and Chinese brand names all represent local Malaysian brands.

Hence, in the context of food brand names using different languages that represent the three major ethnic groups in Malaysia, it is found that Malaysian consumers perceive the Bahasa Malaysia, Tamil and Chinese languages to be representative of Malaysian brand names and acknowledge that these languages suit the local culture. This in turn influences them to purchase the brand names accordingly. In addition, pertaining to the local brands, the study of DeRun and Fah (2006) found that the use of Bahasa Malaysia and Chinese in food packaging can influence local consumers to purchase the products. This is true when the present Malaysian market is observed; many of the local brands are found to be in Bahasa Malaysia, Chinese and Tamil languages. In reality, many of the popular food brand names are Chinese brand names such as Hwa Tai, Hup Seng and Aik Cheong, exist alongside the Bahasa Malaysia brand names such as Jati, Saji and Buruh, and Tamil brand names such as Alagappas and Babas. This study also empirically verifies that ethnic languages in a brand name may indirectly indicate the origin of the brand. Additionally, it can be concluded that a language used in a brand name is a potential source of culture of brand origin when ethnicity is mirrored by a language. More significantly, this study discovers that Bahasa Malaysia, Tamil and Chinese languages imply local culture, which has a significant influence on purchase intention of these brand names. This is in line with Samli's (1995) notion that the local culture has a strong influence on consumer behavior and individual identity. In the study of Steenkamp, Batra and Alden (2003), who investigated brands to be perceived as icons of the local culture in the United States and Korea, it was also found that a positive direct relationship exists between the local brands and purchase intention. Therefore, in the Malaysian context, when Malaysian consumers acknowledge the languages of brand names (Bahasa Malaysia, Tamil and Chinese) to be reflecting the Malaysian subcultures, this can in fact significantly influence their purchase intention 
towards the brand names.

It is also noted that the identification of local culture with the English brand name yielded a non-significant relationship with the purchase intention. This is mainly due to the fact that English brand name is perceived to be relevant to a foreign culture rather than the local culture. Information from Tables 1 and 2 provide evidence for this fact which indicates that 49 percent of the respondents perceived the English brand name to fit a foreign culture and 41.7 percent of respondents believed that the English brand name is a foreign product. The results of this study are contradictory to the fact that English is the second Malaysian official language (The Language Act, Constitution of Malaysia: Article 152 and revised Article 171) and this language is learned at local schools and universities. Malaysians still perceive English as a foreign language when the language is used in a brand name and this leads to the perception that the brand is supposed to have originated from a foreign country. This perception is understandable as many of the English brand names on the Malaysian market are indeed foreign brands. At the same time, there is also a strong proclivity for the local manufacturers to use English names for their brands. Therefore, a profusion of locally-manufactured products with English brand names are widely available in Malaysia as the mentality of a majority of Malaysian consumers infers that foreign products are better in quality than the local ones, due to the projected image of 'foreignness' (Mohamad, et. al., 2000). In spite of this, it was found that Malaysians would still prefer to purchase an English brand name if they could afford it, even though the language of the brand name has been identified as representing a foreign culture.

In this current study, it was found that the evaluation of "the word" (or morphology) positively influences the purchase of Chinese, Tamil and English brand names. Perception of the word in Bahasa Malaysia is found to be not significant on its relationship with purchase intention of the brand name. This may indicate that for the Bahasa Malaysia brand name, Jati, the word of the brand name is not an important factor for respondents in their decision to purchase the brand name unless the name is something contemporary. In other words, the choice of the word needs creativity which can lure consumers to the brand. In fact, some scholars have stressed the importance of word choice in a brand name, by which a modern brand name can greatly influence the success of the brand. For example, Chan and Huang (1997) argued that a brand name must be a modern and a contemporary name. In addition, McNeal and Zeren (1981) highlighted that it is important for managers to understand that a brand name for their products must be a modern name which will influence the success of the product. The importance of the Bahasa Malaysia brand name being different from an ordinary name such as Jati (this word can be found in the Malay dictionary) is enormously important. This is due to the fact that in the Malaysian market, the food packaging industry for example, is observed to be saturated with Bahasa Malaysia brand names. Some examples are Purnama, Kami, Saji, Rindu, Nona, Jati, Syok, Cinta, Desa Kita; and all of these brand names are common and simple Bahasa Malaysia words. Furthermore, these words can be found in the Malay dictionary. Thus, this finding indirectly suggests that a Bahasa Malaysia brand name can only survive in the abundance of Bahasa Malaysia brand names in the market when it is formed by a word that is outstanding and noticeable among the plenty. In addition, the word for a Bahasa Malaysia brand name should not necessarily be a name that is simple and easy to remember.

In spite of the argument above, the words of the Tamil, Chinese and English brand names are found to be significant predictors for purchase intention of these brand names. It is noted that Tamil and Chinese languages are spoken by the Indian and Chinese ethnic groups respectively. And to the Malays who comprise 60 percent of the total population in this study, they may find that the words (Alagappas and Singlong) are unfamiliar words to them. Realizing this fact, this finding suggests that the Malay consumers rely on a simple morpheme for the Chinese and Tamil brand names so that they may able to recognize and remember the names easily. These are the essential factors that Malay consumers are looking for when they make a decision to purchase Chinese and Tamil brand names. In contradiction to the Bahasa Malaysia brand name as mentioned earlier, it is shown that the Chinese and Tamil brand names which are easily recognized and remembered will simultaneously generate interest among consumers to purchase the brand. This provides a meaning that a decent and a simple word for Chinese and Tamil brand names are the influential factors that will attract consumers to buy the brands.

The relationship between the phonology and purchase intention is examined mainly to confirm the conceptualization made by Chan and Huang (1997). Their studies indicated that brand name characteristics, primarily from language sound (phonology) which is properly produced, would be one of the important factors that can influence consumer behavior. It bears highlighting here that a finding of this study is that the influence of perception regarding the sound of a brand name on purchase intention only exists with the examined Tamil brand name. Therefore, the perception of the sound of a brand name is presumed to be a weak predictor for purchase intention of a brand name when the significant relationship of the variables exists only with the Tamil brand name. It was also found that the perception towards the sound of the remaining brand names (Jati, Singlong and Life) do not show any significant relationship with the purchase intention of the brands. 
The findings have validated the significant relationship between the meaning (semantics) and the intention to purchase the brand name. This relationship is found in a positive correlation, particularly for the Bahasa Malaysia, Tamil and English brand names. Even though there is a lack of empirical evidence to support the relationship, the significant positive relationship is expected following the proposition made by Chan and Huang (1997) who conceptualized that when a brand name is formed by the right linguistic properties in terms of its word, sound and meaning, this substantial combination would create the critical factors that can lure consumers to purchase the brand name. Accordingly, each brand name in this study carries its own meaning: the Jati brand name means genuine; Alagappas connotes a handsome father; Singlong means prosperity; and Life denotes living things or quality of life. Therefore, the finding of this current study lends support to Chan and Huang's (1997) conceptualization of the relationship between the meaning and purchase intention of a brand name, whereby it is identified that the meaning of a brand name can affect purchase intention of a brand. Furthermore, the semantic properties of a brand name can benefit consumers in understanding the brand benefits or attributes that are related to the brand (McCarty and Perreault, 1987). Thus, this provides a picture that these three brand names carry positive semantic values, such as: the brand's meaning is appealing; the meaning indicates product attributes; the meaning is unique; and the meaning suggests product quality. In summary, this result is in line with the suggestion made by Opatow (1985) and Stern (1983) who suggested that the word of brand names must indicate product attributes and convey the benefits of the brand. The findings of this present study appear to support Chan and Huang's (1997) deliberation on the importance of a brand name having a generic meaning, in other words the word is a lexicalized item in a dictionary. More importantly, it is found that a comprehensible brand name is a substantial reason for consumers to purchase a food brand name.

\section{Conclusion}

The main contribution of this study is to understand the important implications of culture of brand origin (COBO) to consumer behavior. Empirical evidence of this study suggests that the language of a brand can signal the cultural origin of the brand, and it can influence consumers' acceptance of the brand. Apparently, the language of a brand can be utilized as an important positioning tool. It is understood that Malaysian consumers perceive Bahasa Malaysia a representative of the local culture and this impression of local origin is not given by the English brand name, even though the language has become the second official language of the country. Therefore, local managers must pay greater attention to the language used for their brand names as this study substantiated the importance of language of a brand as an indication of the specific culture behind the product it carries. By emphasizing Malaysian cultural values, especially the use of Bahasa Malaysia language, strong local image can be created. English branding is recommended if the product caters for a premium market. The use of English in fact, can enhance the brand quality image using foreign image (Steenkamp, Batra and Alden 2003). Therefore, managers may exploit the non-local perception of brands via the English brand name to enhance the quality and the image of the brand.

Pertaining to brand name linguistics, this study provides empirical evidence highlighting the influence of brand name linguistics on consumer purchase intention of the brand. Hence, local managers must acknowledge the importance to understand the linguistic characteristics of a brand name, such as its morphological, phonological and semantic aspects. For example, managers are recommended to contemplate a word that is simple and short, as these attributes can aid consumers to quickly recognize the brand name. However, a short and simple brand name is not the essential aspect of a Bahasa Malaysia brand name, in which the true imperative is that the name must able to capture the interest of local consumers. For that reason, it is vital for a Bahasa Malaysia brand name to be a word that is unique, modern, sophisticated besides being outstanding and different from the existing Bahasa Malaysia brand names in the market. Therefore, a common word should not be used at all. The findings of this study reinforce the need for managers to understand that a brand name must clearly communicate the benefits of the product. This can only be achieved when the meaning of the brand name is comprehensible and, more importantly, its meaning precisely indicates the benefits and attributes of the product. These factors are found to have an influence on the purchase of the brand.

The limitation of this study concerns the extent to which its findings can be generalized. The use of non-probability sampling for this study is mainly gauged from its mall intercept interviews; which leads to the conclusion that the findings cannot be statistically projected onto the whole population. In addition, this study is confined to evaluating food brand names; therefore, the findings of this study cannot be generalized to other product categories. In other words, there is ample room for future studies to investigate the influence of $\mathrm{COBO}$ on other product categories. Perhaps future studies can address this limitation by extending this research design to different product categories that consist of a mixture of low and high involvement products, to shed some light on the universality of the results presented here

In summary, СOBO can be a more flexible and effective branding tool than $\mathrm{COO}$ because a brand name can be 
adapted through the use of its language and linguistic properties to correspond with the target group of consumers. Thus, it can be recommended to marketing managers to take into account the important factors of linguistics so as to imply the origin of the product. It is crucial to keep in mind that these factors can be easily manipulated at the production level. Therefore, marketing managers and academics may utilize COBO to further evaluate the brand name origin effect at product development level by investigating linguistic factors as indicators of brand origin.

\section{References}

Amran H., Nabsiah A.H., Osman, M. \& Jeny I. (2011). The concept of culture of brand origin (COBO). A new paradigm in the evaluation of origin effect. International Journal of Academic Research in Business and Social Sciences, 1(3), 282-290

Banks, A.S., \& Textor (1963). R.B. A cross policy survey. Cambridge, MA: M.I.T Press

Barry, L.L., Lefkowith, E.F., \& Clark, T. (1988). In Services, what's in a name? Harvard Business Review, (Sept-Oct), 28-30

Batra, R., Ramaswamy, V., L. Alden, D., M. Steenkamp, J.B.E \& Ramachander, S. (2000). Effects of brand local and non-local origin on consumer attitudes in developing countries. Journal of Consumer Psychology, 9(2), 83-95

Beebe, L.M., \& Giles, H. (1984). Speech accommodation theory: a discussion in terms of second language acquisitic. International Social Language, 46, 5-32

Boddewyn, N.R., Soehl, R., \& Picard, J. (1986). Standardization in international market, is Ted Levitt in fact right. Business Horizons. 29(Nov/Dec), 69-75

Campbell, D.T., \& Fiske, D.W. (1959). Convergent and discriminant validation by the multitrait-multimethod matrix. Psychological Bulletin, 56(1), 81-105

Chan, A., \& Huang, Y.Y. (1997). Brand naming in China: a linguistics approach. Marketing Intelligence and Planning, 15(5), 227-234

Chan, J.F., Warden, C.A., \& Chang, H.T. (2006). Is English a brand: the impact of English language learning on product evaluation? The Journal of Language for International Business, 17(1), 29-42

Chen, J.F., Warden, C.A., \& Chang, H.T. (2006). Is English a brand: the impact of English language learning on product evaluation? The Journal of Language for International Business, 17(1), 29-42

Cohen, J. (1998). Statistical power analysis for the behavioral sciences. Hillsdale, Nj: Erlbaum

Czinkota, M.R., \& Ronkainen, L.A. (1995). International Marketing (4th ed) Toronto, ON: Dryden

De Mooij, M. (1998). Global marketing and advertising. Sage: Thousand Oaks, CA

DeRun, F.C., \& Fah, C.S. (2005). Language used in packaging: Malays and Chinese consumers' reaction. Proceeding of Asian Pacific Marketing Conference 2005

Deshpande, R., \& Stayman, D.M. (1994). A tale of two cities: distinctive theory and advertising effectiveness. Journal of Marketing Research, $31(1), 57$

Giles, D.M., \& Powerland, P.F. (1975). Speech style and social evaluation. London: Academic Press.

Grace, D \& O'Cass, A. (2005). Examining the effects of service brand communications on brand evaluation. Journal of Product and Brand Management, 14(2), 105-116

Hair, J.F., Anderson, R.E., Tatham, R.L., \& Black, W.C. (1998). Multivariate data analysis. New Jersey: Prentice Hall International Inc.

Herche, J. (1990). The measurement of consumer ethnocentrism: revisiting the CETSCALE. In B. Dunlap (ed.) Development in Marketing Science: Miami, F.L: Academy of Marketing Science

Karande, K. (2004). Minority response to ethnically similar models in advertisements: an application of accommodation theory. Journal of Business Research, 58, 1573-1580

Koslow, S., Shamdasani, P.N., \& Touchstone, E. (1994). Exploring language effects in ethnic advertising: A sociolinguistic perspective. Journal of Consumer Research, 20, 575-585

Lerclerc, F. Schmitt, B., \& Dube, L. (1994). Foreign branding and its effects on product perceptions and attitudes. Journal of Marketing Research, 31(2), 263-70

Leonidou (1996). Product standardization or adaptation: the Japanese approach. Journal of Marketing Practice: Applied Marketing Science, 27(4), 53-71

Lerman, D. (2003). The effect of morphemic familiarity and exposure mode on recall and recognition of brand names. Advances in Consumer Research, 30, 80

Lim, K. \& O'Cass, A. (2001). Consumer brand classification: An assessment of culture of origin vs. COO. Journal of Product and Brand Management, 10(2), 120-136

Li, F., \& Shoostari, N.H. (2003). Brand naming in China: Sociolinguistics implications. Multinational Business Review, 11(3), 3-21

Malhotra, N.K. (1999). Marketing research: an applied orientation. $2^{\text {nd }}$ edition. Prentice Hall: International Edition

McCarthy, E.J., \& Perreault, W.D. (1987). Basic Marketing: a managerial approach. Hommerwood, Illinois: Irwin

Mcneal, J.U., \& Zeren, L.M. (1981). Brand name selection for consumer products. MSU Business Topics, 29, 35-39

Mohamad. O., Ahmed, Z.U., Honeycutt, E.D., \& Tyebkhan, T.H. (2000). Does made in matter to consumers? A Malaysian study of country of origin effect. Multinational Business Review, 8(2), 69-75

Opataw, L. (1985). Creating brand name that work. Journal of Product Innovation Management, 2, 254-58

Pallant, J. (2001). SPSS survival manual: a step by step guide to data analysis using SPSS for windows (version 10). Victoria: McPhersons Printing Group 
Pan, Y., \& Schmitt, B. (1996). Language and brand attitudes. Impact of script and sound matching in Chinese and English. Journal of Consumer Psychology, 5(3), 263-277

Peterson, R.A., \& Jolibert, A.J.P. (1995). A Meta-analysis of country of origin effects. Journal of International Business Studies, 26(4), 883-896

Samli, C. A (1995). International consumer behavior: its impact on marketing strategy development, Qourum Books: Westport, Ct.

Schuiling, I., \& Kepferer, J.N. (2004). Executive insights: real differences between local and international brands. Strategic implications for international marketing. Journal of International Marketing, 12(4), 97-112

Schmitt, B. H., \& Zhang, S. (1998). Language structure and categorization: A study of classifiers in consumer cognition, judgment and choice. Journal of Consumer Research, 25(September), 108-122

Spears, N., \& N. Singh, S. (2004). Measuring attitude toward the brand and purchase intention. Journal of Current Issues and Research in Advertising, 26(2), 54-65

Steenkamp, M., Batra, J.B, \& Alden, L. (2003). How perceived brand globalness creates brand value. Journal of International Business Studies, 34(1), 53-65

Stern, W. (1983). A good name could mean a brand of fame. Advertising Age, 54, 53-54

Suh, T \& Kwon, I.W. (2002). Globalization and reluctant buyers. International Marketing Review, 19(6), 663-679

Terpstra, V., \& Sarathy, R. (1997). International Marketing (7th ed.): Dryden Press.

Thakor, M.V., \& Kohli, C.S. (1996). Brand origin: Conceptualization and review. Journal of Consumer Marketing, 13(3), 27-42

Usunier, J.C. \& Shaner, J. (2002). Using linguistics for creating better international brand names. Journal of Marketing Communication, 8, 211-228

Warden, C.A., Lai, M.K., \& Wu, W.Y. (2002). How worldwide is marketing communication on the World Wide Web? Journal of Advertising Research, 43(1), 72-84

Whorf, B.L. (1941). The relation of habitual thought and behavior to language. In Leslie Spier (ed.) Language, Culture and Personality, Essays in Memory of EdwardSapir, 75-93. Meansh, WI: Sapir Memorial Publication Fund

Yacob, S. (2005). Political culture and nation building: unrealised dream? The struggle for 'Bangsa Malaysia'. Unpublished paper. Department of History, University of Malaya. Kuala Lumpur, Malaysia

Zablah, A. R., Brown, B. P., \& Donthu, N. (2010), "The relative importance of brands in modified rebuy purchase situations", International Journal of Research in Marketing, 27(3), 248-260. 